\title{
Observed and Modeled Changes in the South Asian Summer Monsoon over the Historical Period*
}

\author{
Fangxing Fan, Michael E. Mann, Sukyoung Lee, and Jenni L. Evans \\ Department of Meteorology, and Earth and Environmental Systems Institute, The Pennsylvania State University, \\ University Park, Pennsylvania
}

(Manuscript received 10 August 2009, in final form 26 April 2010)

\begin{abstract}
The behavior in the South Asian summer monsoon (SASM) was analyzed in Coupled Model Intercomparison Project (CMIP3) multimodel historical $(20 \mathrm{c} 3 \mathrm{~m})$ simulations and in modern observational and reanalysis data. The CMIP3 simulations capture the observed trend of weakening of the SASM circulation over the past half century, but are unable to reproduce the magnitude of the observed weakening trend. While the observations indicate a slight decrease in SASM-related precipitation, the CMIP3 simulations indicate on average a very slight increase, albeit with very large intermodel and intramodel variabilities. The CMIP3 simulations reproduce the observed negative relationship between the SASM and ENSO. The observed weakening trend in this relationship in recent decades, which has been attributed in some studies to anthropogenic forcing, appears to be well within the variability of the CMIP3 multimodel ensemble. For some models, distinct realizations indicate both strengthening and weakening trends that are larger in magnitude than the observed weakening trend.
\end{abstract}

\section{Introduction}

The South Asian summer monsoon (SASM), a subcomponent of the larger Asian monsoon system (Ding et al. 2004), represents a key feature of our current largescale atmospheric circulation. The SASM is characterized by a monsoon trough along the Indo-Pakistan plains (Blanford 1886), lower-level westerlies associated with the convergence of surface moisture (Joseph and Raman 1966), and an upper-level easterly jet stream (Koteswaram 1958). The strength of the South Asian summer monsoon is often indicated by monsoon circulation indices [e.g., the Webster and Yang index; Webster and Yang (1992)] and monsoon precipitation [e.g., the All-India monsoon rainfall (AIMR) index; see Parthasarathy et al. $(1992,1994)]$. The SASM accounts for almost $70 \%$ of the annual mean precipitation over the Indian subcontinent,

\footnotetext{
* Supplemental information related to this paper is available at the Journals Online Web site: http://dx.doi.org/10.1175/ 2010JCLI3374.s1.

Corresponding author address: Fangxing Fan, Department of Meteorology, The Pennsylvania State University, 408 Walker Building, University Park, PA 16802.

E-mail: fxf908@psu.edu
}

providing essential freshwater resources to that region. Given its societal relevance, it is of considerable importance to document the historical changes in the SASM and to isolate the roles of various natural and anthropogenic factors in the observed changes in SASM behavior.

Two primary anthropogenic forcings, increased greenhouse gas concentrations and tropospheric sulfate aerosol, represent competing factors potentially influencing the SASM through altering the land-sea differential heating (Halley 1686; Holton 1992; Webster et al. 1998). Greenhouse warming appears to increase SASM precipitation due to the associated increase in the water vapor mixing ratio (Meehl and Washington 1993; $\mathrm{Hu}$ et al. 2000; May 2002; 2004; Meehl and Arblaster 2003), but may actually weaken the strength of the SASM circulation itself by stabilizing the atmosphere via enhanced midtropospheric latent heating (Kitoh et al. 1997; Douville et al. 2000). This so-called wind-precipitation paradox is discussed further below. Any tendency for increased SASM precipitation, moreover, is likely offset by the impacts of tropospheric sulfate aerosols, which decrease the surface shortwave forcing, the differential heating, and hence the SASM's strength and precipitation (Meehl et al. 1996; Mitchell and Johns 1997). Indentifying the precise impact of anthropogenic forcing on the SASM is further complicated by other less well 
constrained impacts, such as black carbon and organic carbon (Menon et al. 2002; Ramanathan et al. 2005; Ramanathan and Carmichael 2008).

The SASM is also influenced by the El Niño-Southern Oscillation (ENSO) through the displacement of the Walker circulation (Latif et al. 1994; Nigam 1994; Ropelewski and Halpert 1987, 1989). El Niño (La Niña) events tend to be associated with a weaker (stronger) than normal SASM (Kripalani and Kulkarni 1997; Kripalani et al. 2001, 2003; Rasmusson and Carpenter 1983). The relationship between ENSO and the SASM has changed in recent decades, which could be attributed to either anthropogenic forcing (Krishna Kumar et al. 1999) or natural variability (Kripalani and Kulkarni 1997; Mehta and Lau 1997; Gershunov et al. 2001; Ashrit et al. 2001, 2003).

Before projections of future changes in the SASM can be meaningfully evaluated, it is necessary to first evaluate the ability of the current generation of climate models to reproduce observed historical variations in the SASM and their relationship with other climate factors such as ENSO. Thus, we will first assess historical (nineteenthtwentieth century) simulations of state-of-the-art coupled atmosphere-ocean general circulation models (AOGCMs) taken from phase 3 of the World Climate Research Programme's (WCRP) Coupled Model Intercomparison Project (CMIP3) multimodel intercomparison project. We focus on the extent to which the various models are able to capture the observed trends in SASM strength and SASM-related precipitation, to reproduce the known ENSO-SASM relationship and, potentially, the recent changes therein.

In section 2 we provide some additional background, reviewing the wind-precipitation paradox critical to interpreting possible anthropogenic trends in SASM strength and SASM-related precipitation as well as the current understanding of the ENSO-SASM relationship. In section 3, we review the model simulations analyzed and the methods used to evaluate the SASM behavior in the simulations. In section 4, we present the results of our analysis of the trends in the SASM behavior and the ENSO-SASM relationship. Conclusions follow in section 5 .

\section{Background}

\section{a. Anthropogenic responses and the wind-precipitation paradox}

The concept of the wind-precipitation paradox was raised by Kitoh et al. (1997) based on an analysis of a global coupled AOGCM simulation forced with increasing greenhouse gases, which indicated a decrease in the strength of SASM winds in spite of the increase in the Indian summer monsoon rainfall accompanying global warming. Wang (2006) explained this paradox in terms of a northward shift of the monsoon circulation, as simulated by some climate models (Kitoh et al. 1997; Ashrit et al. 2003, 2005). However, the basic mechanism of the paradox can also be understood from the following dynamical perspective.

We start with the Boussinesq approximation of the omega equation:

$$
\nabla^{2} w+\frac{f_{0}^{2}}{N^{2}} \frac{\partial^{2} w}{\partial z^{2}}=\frac{1}{N^{2}}\left(\nabla^{2} Q-f_{0} \frac{\partial F_{\zeta}}{\partial z}\right),
$$

where $w$ is the vertical velocity $\left(\mathrm{m} \mathrm{s}^{-1}\right), f_{0}$ is the Coriolis parameter $\left(\mathrm{s}^{-1}\right), N$ is the buoyancy frequency $\left(\mathrm{s}^{-1}\right), Q$ is the diabatic heating (which increases with anthropogenic greenhouse warming), and $F_{\zeta}$ is the vorticity sourcesink.

Assuming that the horizontal and vertical scales of $w$ are $L$ and $D$, respectively, the order of magnitude for $w$ can be scaled as

$$
w \approx \frac{L^{2}}{N^{2}}\left(1+\frac{L^{2} f_{0}^{2}}{N^{2} D^{2}}\right)^{-1} \max \left(\nabla^{2} Q, f_{0} \frac{\partial F_{\zeta}}{\partial z}\right) .
$$

Provided that $L$ and $D$ are held fixed, according to (2), changes in the vertical velocity $w$ can occur either through changes in $\nabla^{2} Q$ or $N$, or through changes in the vorticity source-sink. This vorticity source-sink includes both transient and stationary eddy fluxes and because both of these terms undergo changes in response to climate warming, the change in the vorticity source-sink may also play a role in both the observed and simulated trends in $w$.

Even if this effect can be ignored, and only changes in $\nabla^{2} Q$ and $N$ are considered, the response of $w$ is not straightforward to predict. On one hand, the magnitude of the vertical velocity $w$ and the monsoon circulation will tend to increase as $Q$ increases in accordance with the increased gradient in longwave heating (which arises because the warming is greater over land than ocean, at least in the transient greenhouse response). However, we also know that the atmospheric water vapor content will increase, leading to increased SASM precipitation, and hence increased midtropospheric latent heating, in the region of the rising limb of the SASM circulation. This heating will increase the midtropospheric dry static stability, thus increasing $N$, and hence tending to diminish the magnitude of the vertical velocity $w$ and the circulation. Thus, while the increased latent heating can further enhance $Q$, the attendant increase in static stability can weaken the circulation. These considerations 
provide an interpretation for the decoupling of trends in the SASM strength and SASM precipitation during the twentieth century. However, there is an additional complication in that the static stability also depends on the midlatitude eddy fluxes, which are also shown to respond to warming (e.g., Bengtsson et al. 2006) caused, for example, by either increasing greenhouse gas concentrations or absorbing tropospheric aerosol heating (Ramanathan and Carmichael 2008). As such, there are multiple, interconnected, processes that influence both $Q$ and $N^{2}$, and thus the extent of the decoupling of trends in the SASM strength and precipitation in the climate models likely depends on the model's ability to faithfully simulate all of these processes.

\section{b. The ENSO-SASM connection}

The relationship between ENSO and the SASM circulation and associated rainfall has been discussed in a number of previous studies (e.g., Rasmusson and Carpenter 1983; Kripalani and Kulkarni 1997). SASM indices are found to be significantly anticorrelated with ENSO indices during the following boreal winter, and there is an associated deficit in SASM-related rainfall known as "monsoon failure" (Grove 1998). The conventional view of the ENSO-SASM teleconnection (Krishna Kumar et al. 1999) involves the displacement of the Walker circulation due to ENSO-related SST anomalies in the central-eastern equatorial Pacific. In an El Niño event, the associated shift in the Walker circulation leads to increased subsidence over a broad region stretching from the western Pacific through South Asia. The increased subsidence weakens the tendency for convection and rainfall over South Asia typically associated with the SASM. La Niña conditions, through similar reasoning, are associated with opposite tendencies in the SASM.

The relationship between the ENSO and SASM changes on decadal and longer time scales. These changes could be associated with the effects of global warming through the southeastward shift of the Walker circulation and a decrease in Eurasian snow cover (Krishna Kumar et al. 1999). It is also possible that low-frequency natural variability (Mehta and Lau 1997; Gershunov et al. 2001), or of course some combination of natural and anthropogenic influences, modulates this relationship.

\section{Models and methodology}

\section{a. Model properties}

We analyzed the twentieth-century experiment (20c3m) AOGCM simulations from the CMIP3 archive (information online at http://www-pcmdi.llnl.gov/ipcc/about_ipcc. php). The various AOGCMs used in this project differ in the numerical schemes and physical parameterizations used in the atmospheric, ocean, sea ice, and land surface components, and in their treatment of atmospheric chemistry, biogeochemistry, aerosols physics, dynamic vegetation, and ice sheet physics. Most of the models do not employ any form of flux adjustment. Atmospheric model resolution varies from roughly $1^{\circ}$ to $5^{\circ}$ in latitude and longitude. Detailed information is available online (http://www-pcmdi.llnl.gov/ipcc/model_documentation/ ipcc_model_documentation.php).

The 20c3m experiments in the CMIP3 archive comprise 51 simulations using 23 different state-of-the-art AOGCMs. The models were forced with estimated anthropogenic (greenhouse gases, sulfate aerosols, stratospheric ozone) and, to varying extent, natural (solar and volcanic) radiative forcings and extend over all or most of the period 1850-1999/2000. We focused on the latter half of the twentieth century (1948-1999/2000) during which time it is possible to compare the simulations against the modern reanalysis observations.

\section{b. Defining indices of the monsoon and ENSO}

To assess the behavior of the SASM in these simulations, we have used a previously derived methodology for defining an integrative monsoon index (IMI) in terms of the common pattern among multiple atmospheric fields (sea level pressure, zonal tropospheric wind shear, and meridional tropospheric wind shear) associated with the monsoonal dynamics (Fan et al. 2009). Importantly, monsoon-related precipitation is not used as a defining variable, due to its potential for decoupling from the monsoon dynamics, as discussed above in section 2 .

The procedure for defining the IMI involves taking the leading principal component (PC) time series of a reduced space representation of the above three fields, over the appropriate spatial domain. In the case of the SASM, the spatial domain is defined by the SASM region $\left(0^{\circ}-60^{\circ} \mathrm{N}, 40^{\circ}-105^{\circ} \mathrm{E}\right)$ and the fields are averaged over the boreal summer (June-August, JJA) season. The reduced space representation consists of four leading empirical orthogonal function (EOF)-PC pairs of the three fields (both of the first two EOF-PC pairs are used in the case of the meridional wind shear, as they are typically found to have nearly degenerate eigenvalues; the leading PCs of the sea level pressure and zonal wind shear explain $37 \%$ and $29 \%$ of the variance, respectively, averaged over all 51 individual simulations, while the first two PCs of the meridional wind shear combined account for less than $20 \%$ of the variance; see Tables S1 and $\mathrm{S} 2$ in the online supplement to this paper). The IMI is standardized to have zero mean and unit variance. As shown by Fan et al. (2009), the IMI procedure yields a very similar index of the SASM to other SASM indices 
defined in terms of features of the boreal summer climatology (e.g., Webster and Yang 1992; Goswami et al. 1999). However, a critical advantage of our procedure over such approaches, particularly within the context of the current analysis, is that it is universal in nature, defined only on anomaly fields rather than on specific climatological features, which vary greatly from model to model. With one notable exception [one of the two National Aeronautics and Space Administration (NASA) Goddard Institute for Space Studies Model E-H (GISSEH) simulations], positive values of the IMI in each of the $20 \mathrm{c} 3 \mathrm{~m}$ simulations analyzed are characterized by the familiar features of the observational SASM: a broad surface low pressure trough over tropical South Asia; positive zonal wind shear over the region $5^{\circ}-20^{\circ} \mathrm{N}, 40^{\circ}-$ $110^{\circ} \mathrm{E}$ (Webster and Yang 1992); and a zonal tripolar structure in the meridional wind shear field (see Fan et al. 2009). Time series of the leading PCs for the three constituent fields are shown for the entire multimodel ensemble as well as for the ensemble mean in the online supplement (Fig. S1).

We performed a set of tests to assess the sensitivity of the results to the domain used to define the SASM, using three representative simulations from the CMIP3 archive (see section S4 of the online supplement). These tests employed an alternate domain that is substantially smaller $\left(0^{\circ}-40^{\circ} \mathrm{N}, 60^{\circ}-105^{\circ} \mathrm{E}\right)$ than the standard domain $\left(0^{\circ}-60^{\circ} \mathrm{N}, 40^{\circ}-105^{\circ} \mathrm{E}\right)$ defined above. These domain sensitivity tests demonstrated the results to be robust to the choice of either domain. The resulting EOF patterns display similar features, and the SASM IMI series diagnosed from these two domains exhibit an extremely high correlation ( $r=0.899,0.967$, and 0.984 , respectively, for the three simulations; $p<<0.001$ in each case).

In general, the models capture the climatological pattern of the SASM-related precipitation in South Asia quite well, though there is a fair amount of variation between the models in the precise pattern (see Fig. S2 in the online supplement). We considered two alternative metrics of SASM-related precipitation to ensure some degree of robustness with respect to how this quantity is defined. The first metric is defined by the leading EOF-PC of JJA precipitation over the larger SASM region defined above (with the sign of the series defined to yield positive loadings over the South Asian region of monsoon-related precipitation). This metric explains $8 \%-26 \%$ of the variance in the 51 simulations (Table S1 in the online supplement). The second metric is simply the mean JJA precipitation over all of the model grid boxes that fall within the Indian subcontinent. For both precipitation metrics, the associated time series is standardized to have zero mean and unit variance.
Detailed results are shown in the online supplement (Tables S2 and S3, Figs. S4 and S5) for the analysis of one particular model [the Model for Interdisciplinary Research on Climate 3.2, medium-resolution version; MIROC3.2(medres)] as an illustrative example. The results shown are representative of the results obtained for all models, demonstrating that the SASM IMI is associated with dynamically consistent patterns in the three constituent fields, as well as the pattern of summer rainfall over the SASM region.

For purposes of assessing relationships with ENSO, we employed the results from an analysis by Sabbatelli et al. (2010, manuscript submitted to Climatic Change, hereafter SMM), which was performed for a slightly more restricted set of the CMIP3 20c3m simulations (23 models and 44 total realizations). In this analysis, a series termed niñograd is defined as the December-February (DJF) equatorial SST zonal gradient (calculated by linear regression of the $10^{\circ} \mathrm{S}-10^{\circ} \mathrm{N}$ meridionally averaged SST grid boxes along the zonal strip $90^{\circ} \mathrm{W}-120^{\circ} \mathrm{E}$ ) normalized to have zero mean and unit variance. This definition appropriately removes the impacts of the overall mean tropical warming from the definition of "ENSOness." While the niñograd series is largely indistinguishable from other standard SST-based ENSO metrics (e.g., Niño-3.4) during the historical interval, the behavior in the twenty-first-century CMIP3 projections is substantially different (SMM). Using niñograd, SMM confirm the finding by Meehl et al. (2007) that the majority (albeit slight, with 8 out of 15 analyzed in their case) of the CMIP3 models project a more El Niño-like mean state in response to increasing greenhouse gas concentrations, but the models are nearly equally split with respect to this measure.

\section{c. Ranking of models}

It is necessary to first evaluate the various models with respect to their fidelity in simulating the SASM. We employed metrics related to SASM rainfall, since direct (rather than only reanalysis based) long-term observations are available for comparison with the model simulations. The first metric is a measure of the SASM mean state, defined simply as the mean total SASM precipitation over June-September averaged over the Indian subcontinent. The second metric is a measure of the SASM variability, defined as the interannual standard deviation in the total SASM precipitation series. As a baseline for comparison, the observed values over the interval 1948-2000 are $848.6 \mathrm{~mm}$ for the total SASM rainfall and $82.5 \mathrm{~mm}$ for the interannual standard deviation. The models errors relative to the observations were defined by the relative measure 

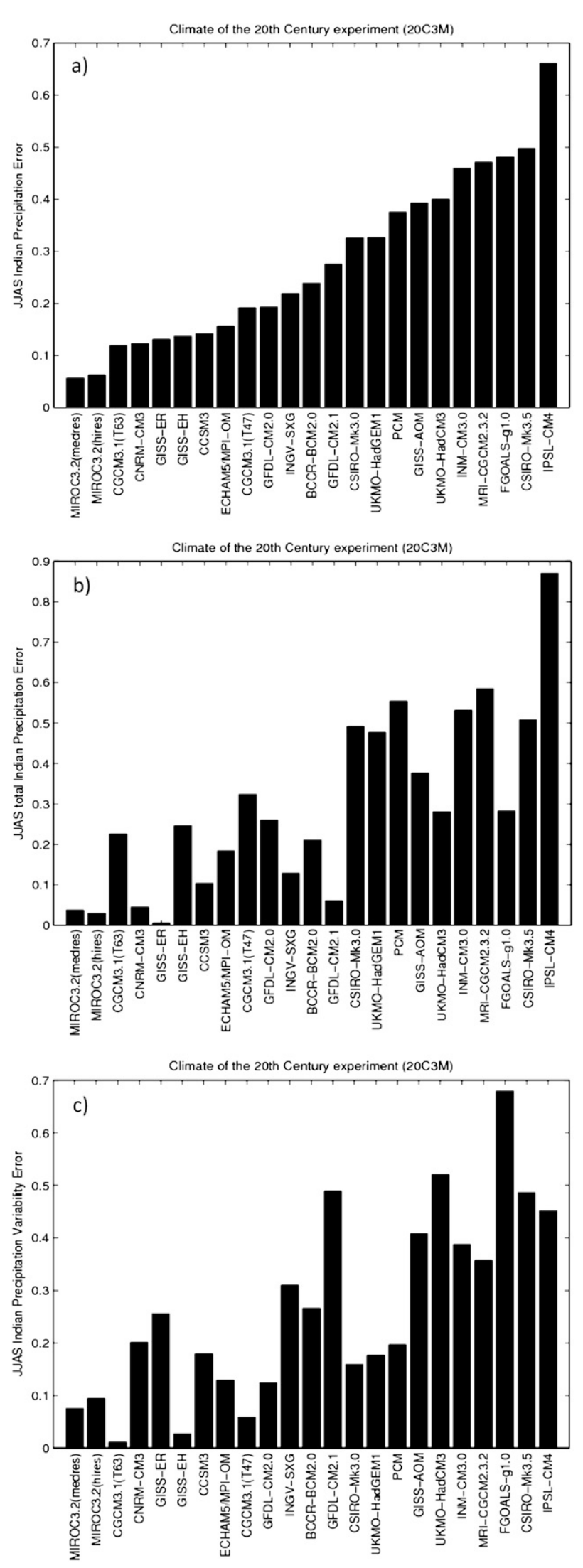

$$
\text { Error }=\frac{\mid \text { Modeled }- \text { Observed } \mid}{\mid \text { Observed } \mid} .
$$

Where multiple realizations of a particular model were available, scores were averaged to get a single representative value for the model. Each of the 23 available models was then ranked in terms of their scores with respect to each of the two metrics, and a composite score was calculated by averaging both metrics (Fig. 1). Models were grouped in terms of their performance as measured by the composite score; we defined "best" as being those models that scored in the upper third (corresponding to a composite relative error of under $15 \%$; there were seven such models), "good" as being those models that scored in the upper half (relative errors under $25 \%$ ), and "worse" as being those models that scored in the lower half (relative errors greater than $25 \%$ ). These relative measures of performance are used later to interpret the disparate results among the various models of the multimodel ensemble. Consistent with the quantitative evaluation above, we also observed qualitatively that the best models generally succeed in reproducing the spatial climatology of the SASM-related precipitation, with regional maxima over the Arabian Sea and Bay of Bengal, and a contrast in precipitation over India from the northwestern dry region to the southeastern wet region well simulated (Fig. S2 in the online supplement).

\section{Analysis of modeled and observed historical SASM}

\section{a. Trends in the SASM circulation and precipitation}

A wide range in the pattern of behavior is observed among the 23 models and 51 simulations of the $20 \mathrm{c} 3 \mathrm{~m}$ CMIP3 archive. Figure 2 shows the temporal evolution over the late twentieth-century interval 1948-1999/2000 of the SASM strength as measured by the IMI, and SASM-related precipitation. Figure 3 compares the net trends over the 1948-1999/2000 interval. The results for the $20 \mathrm{c} 3 \mathrm{~m}$ simulations are compared (Figs. 2 and 3) to results from a parallel analysis of observations over the same time interval (see Fan et al. 2009) based on National

FIG. 1. Errors of the 23 AOGCMs in simulating two metrics related to monsoon precipitation: 1) the total June-September rainfall averaged over the Indian subcontinent and 2) the interannual standard deviation of the total June-September rainfall averaged over the Indian subcontinent. Models are ranked according to the (a) average of two errors, (b) total monsoon rainfall, and (c) interannual standard deviation of the total monsoon rainfall. 

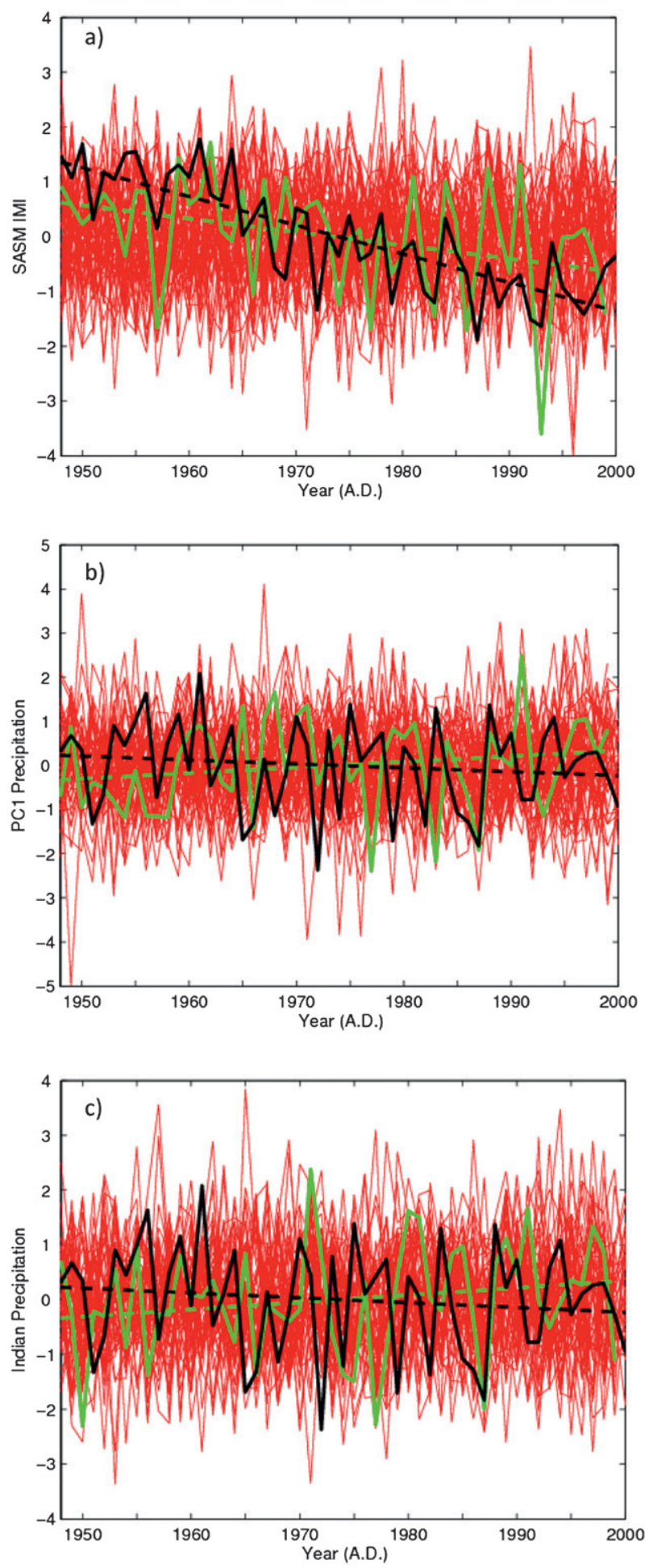

FIG. 2. Time series comparisons of 51 individual 20c3m simulations (red), the multimodel mean (green), and observational (black) data over 1948-1999/2000. (a) Simulated vs observed (NCEPNCAR reanalysis) SASM IMI series. (b) Simulated vs observed (AIMR) SASM-related precipitation, with the model precipitation defined by the leading EOF-PC. (c) As in (b), but when defining the model precipitation as the mean over the Indian grid boxes.
Centers for Environmental Prediction-National Center for Atmospheric Research (NCEP-NCAR) reanalysis atmospheric wind and pressure data (Kalnay et al. 1996) and the AIMR index of Parthasarathy et al. $(1992,1994)$. Results are given both based on averaging over multiple realizations to yield estimates for each of the 23 models (Figs. 3a and 3c) and for all 51 individual realizations (Figs. $3 \mathrm{~b}$ and $3 \mathrm{~d}$ ). Results are also given using both the EOF-PC-based definition of AIMR precipitation (Figs. $3 \mathrm{a}$ and $3 \mathrm{~b}$ ) and the Indian gridbox-based definition (Figs. 3c and 3d).

A weakening trend in the SASM (i.e., a negative trend in the IMI) is highly significant in the observations $(p<$ 0.001 level for a one-sided test). On average, the $20 \mathrm{c} 3 \mathrm{~m}$ models reproduce this tendency, though the trend in the multimodel mean (the average of all 51 realizations) is muted (Fig. 2a). The model spread is large; both increasing and decreasing trends can be found (16 of the 23 models exhibit a decreasing trend; see Fig. 3a). As noted earlier, such a decreasing trend is expected as a response to tropospheric sulfate aerosol forcing and also, perhaps, to greenhouse radiative forcing, through potential increases in the atmospheric static stability. The models, however, are unable to reproduce the magnitude of the observed weakening trend in the SASM, in any one of the 51 available realizations, which sample the expected range of internal as well as forced variabilities (Fig. 2a). It is difficult to determine whether this discrepancy indicates a systematic bias in the responses present in the $20 \mathrm{c} 3 \mathrm{~m}$ models, or the potential biases in long-term trends in the NCEP-NCAR reanalysis data (e.g., Hurrell and Trenberth 1998). There are notable short-term decreases in the multimodel IMI (Fig. 2a) after 1963, 1982, and 1991 that are presumably associated with the short-term weakening influence of the explosive volcanic radiative forcing on the SASM IMI (Fan et al.2009) corresponding to the Agung, El Chichón, and Mount Pinatubo eruptions, respectively. The observational IMI represents just a single realization of the climate, and the internal variability related to ENSO, for example, plays a far more prominent role than in the multimodel mean. Nonetheless, the observational IMI series displays some of the same apparent interannual responses to volcanic forcing seen in the multimodel mean IMI series.

The spatial patterns and interannual variability of the dry static stability, precipitation, and vertical velocity

Linear trends are shown for observations (dashed black) and the
multimodel mean (dashed green). All series have been standardized to have zero mean and unit standard deviation. 

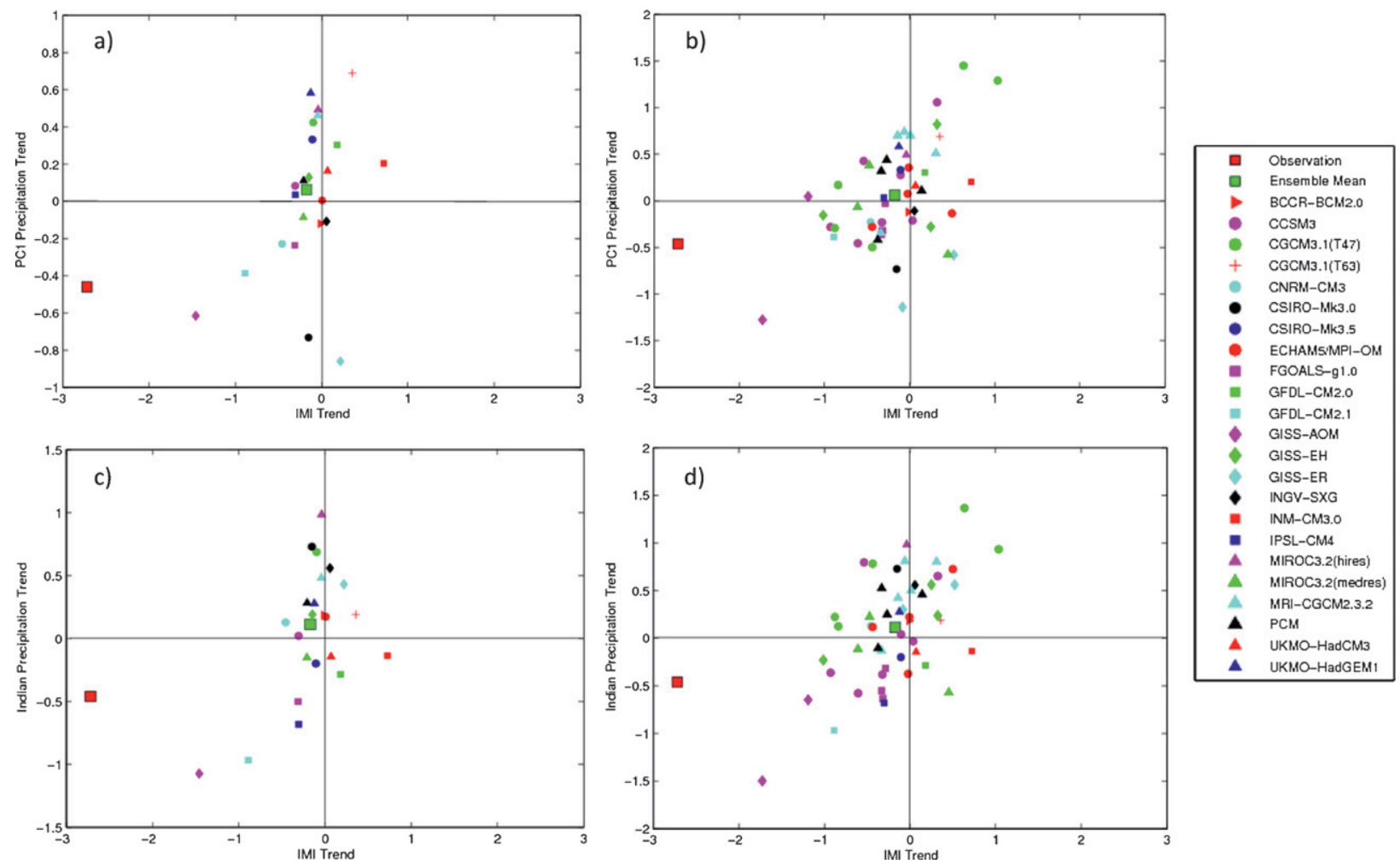

FIG. 3. Change in the SASM circulation strength as measured by IMI (horizontal axes) and change in the SASM-related precipitation (vertical axes) for the 20c3m CMIP3 simulations over 1948-1999/2000. Results from a parallel analysis of observational data (NCEPNCAR reanalysis data and AIMR series) and averages over all models/simulations are shown for comparison. (a) Results for all 23 AOGCMs with results from multiple realizations averaged; the model precipitation is defined by the leading EOF-PC. (b) As in (a), but for all 51 individual realizations. (c) As in (a), but defining the model precipitation as the mean over the Indian grid boxes. (d) As in (b), but defining the model precipitation as the mean over the Indian grid boxes.

associated with SASM IMI are analyzed for one of the "best performing" model simulations (CGCM3.1 T63, run1) (see Fig. S5 in the online supplement). At interannual time scales, positive IMI is associated with increased precipitation and increased (decreased) lower- (upper-) level dry static stability, implying that the convective heating effect dominates over the dry static stability to determine the strength of the SASM circulation. Whether or not these relationships apply to longer, multidecadal time scales is more difficult to evaluate from these simulations due to the short period analyzed and the relatively weak climate forcings during the twentieth century. Work in progress examining these relationships in the CMIP3's twenty-first-century projections should provided more definitive conclusions.

A slight decreasing trend is found for the late-twentiethcentury precipitation observations (Figs. $2 b$ and $2 c$ ), though the trend is not significant ( $p=0.25$ for a twosided test). As noted earlier, any SASM precipitation trends are likely to reflect a competition between the amplifying effects of a warmer, more water vapor laden atmosphere, and the mitigating impacts of sulfate aerosol forcing of the SASM. Thus, it is difficult to specify a priori what sign might be expected for a trend in SASMrelated precipitation. Consistent with this view, the models span a large range of both decreasing and increasing late-twentieth-century trends, and are essentially evenly split on this question, regardless of how SASM precipitation is defined. In contrast to the weak decreasing trend in the observations, the multimodel mean shows a weak increasing trend (Figs. 2b, 2c, and 3). The observed trend falls well within the spread of the models, and even within the spread of the multiple realizations for a given model [e.g., Community Climate System Model, version 3 (CCSM3) or GISS-EH; see Figs. 3b and 3d].

While the average over all 20c3m models and simulations indicates a decreasing IMI and slightly increasing monsoonal precipitation, the variability is large and the relationships between the IMI and precipitation trends vary highly from model to model. Only 9 of the 23 models on average actually exhibit both decreasing IMI and increasing SASM precipitation, with 7 of the models indicating decreases in both, 5 models indicating increases in both, and 2 models indicating an increasing IMI and 
decreasing SASM precipitation, with precipitation defined as leading EOF-PC (the IMI and precipitation trends are actually positively correlated among the 51 distinct simulations; Fig. 3a and 3b).

Confining the ensemble to only the "best performing" models (Fig. S3a in the online supplement), as defined by the performance metrics discussed in section $3 \mathrm{c}$, decreases the spread between the model simulation results somewhat. All but one of the seven best-performing models exhibit an increasing trend in SASM precipitation, though ironically that is the opposite of the observed trend. All but two of the seven models exhibit a decreasing IMI trend. While that trend matches the observed trend in sign, the modeled decrease in IMI is substantially smaller in magnitude than the observed IMI decrease. In one particular simulation of the best model [MIROC3.2(medres)], while the SASM IMI has a decreasing trend (Fig. S4 in the online supplement), the SASM-related precipitation indicates an increasing trend (Fig. S5 in the online supplement) over the 19482000 interval, though neither is statistically significant at the $p=0.05$ level for a two-sided test.

\section{b. SASM-ENSO relationship}

We next investigated the relationship between SASM and ENSO over the same late-twentieth-century (19481999/2000) period for both the observations and the $20 \mathrm{c} 3 \mathrm{~m}$ simulations (restricted in this case to 44 simulations for which ENSO behavior was analyzed). The observational SASM IMI as calculated from the NCEPNCAR reanalysis data is anticorrelated with the DJF Niño-3.4 index $(r=-0.364)$ at the $p<0.01$ level for a one-sided test, consistent with our current understanding of the relationship between the Walker circulation and SASM discussed earlier. In general, the correlations between the SASM IMI and niñograd in the $20 \mathrm{c} 3 \mathrm{~m}$ simulations strongly reproduce this relationship (Table 1 , Fig. 4), with 34 of the 44 individual realizations indicating a negative relationship, 18 of which are significant at the $p=0.05$ level for a one-sided test. For 5 of the 23 models considered [Commonwealth Scientific and Industrial Research Organisation Mark version 3.0 (CSIROMk3.5), ECHAM5/Max Planck Institute Ocean Model (MPI-OM), Geophysical Fluid Dynamics Laboratory Climate Model version 2.0 (GFDL-CM2.0) and version 2.1 (GFDL-CM2.1), Meteorological Research Institute Coupled General Circulation Model, version 2.3.2 (MRICGCM2.3.2)], the negative relationship is substantially stronger than in the observations themselves. Our findings here are consistent with a previous analysis by Annamalai et al. (2007), who investigated the faithfulness of ENSO's influence on the SASM in the 20c3m simulations based on correlations between the AIMR and Niño-3.4 indices. As was the case with the full time period reported in section $4 a$, confining the ensemble to only the best-performing models (Fig. S3b in the online supplement) does little to resolve the discrepancy between the modeled and observed trends. While the spread in the overall ENSO-SASM correlation decreases among the seven best models, these models actually cluster farther from the substantially negative observed correlation than does the full ensemble.

Of equal interest in our analyses is the issue of the apparent weakening of the inverse relationship between the SASM and ENSO in recent decades (Krishna Kumar et al. 1999, 2006; Gershunov et al. 2001). Splitting the 1948-2000 interval into early (1948-73) and late (19742000) periods, we find that the correlation between the SASM IMI and the Niño-3.4 index is indeed substantially lower in the later period $(r=-0.33)$ than in the earlier period $(r=-0.54)$, though in both cases it is still significant at the $p=0.01$ level for a one-sided test.

We performed the same analyses for these "late" and "early" subintervals of the 1948-1999/2000 period in the $20 \mathrm{c} 3 \mathrm{~m}$ simulations. Somewhat surprisingly, we found that significantly larger differences in correlation of both signs (i.e., both greater strengthening and weakening of the inverse SASM-ENSO relationship) were common in the simulations (Fig. 4), even for different realizations of the same model (i.e., the MRI-CGCM2.3.2 model). The average difference in the correlation over all $20 \mathrm{c} 3 \mathrm{~m}$ simulations is very close to zero (Fig. 4). While it has been speculated elsewhere (Krishna Kumar et al. 2006) that the weakening of this inverse relationship might be related to anthropogenic forcing, our findings here suggest that, at least within the context of the CMIP3 simulation models, such a weakening is within the range of the internal decadal variability of the climate, as concluded previously by Gershunov et al. (2001).

When the ensemble is confined to only the seven bestperforming models (Fig. S3b in the online supplement), the models nonetheless remain roughly split with regard to whether a positive or negative late-twentieth-century trend in correlation is predicted, and the largest overall positive and negative trends for the full ensemble both lie within the subensemble of the seven best models. Indeed, for the two best-performing models [i.e., both MIROC3.2(medres) and GISS Model E-R (GISS-ER); see Fig. 4], both positive and negative changes in correlation larger in magnitude than the observed change $(r=+0.21)$ are produced among differing realizations of the same model. These realizations all share a common forced signal, and differ in their patterns of behavior only due to the difference in the particular realization of the internal variability (through differences in model initialization). It is thus clear that the internal variability 
TABLE 1. Correlations between the SASM IMI and El Niño indices (Niño-3.4 for NCEP observations, and niñograd index for simulations) over the full 1948-1998/99 interval, and early (1948-73), and late (1974-1998/99) half intervals for the 23 models (44 realizations) for which ENSO mean state changes have been diagnosed. Negative correlations that are statistically significant at the $p=0.05$ level $(p=$ 0.1 level) for a one-sided test are shown in boldface (italics).

\begin{tabular}{|c|c|c|c|c|}
\hline \multicolumn{2}{|l|}{ Model/observations } & \multirow{2}{*}{$\frac{1948-1998 / 99}{-\mathbf{0 . 3 6 4}}$} & \multirow{2}{*}{$\begin{array}{r}1948-73 \\
-\mathbf{0 . 5 4 0}\end{array}$} & \multirow{2}{*}{$\frac{1974-1998 / 99}{-\mathbf{0 . 3 3 0}}$} \\
\hline NCEP-NCAR reanalysis data & & & & \\
\hline $\begin{array}{l}\text { Bjerknes Centre for Climate Research Climate Model version } 2.0 \\
\text { (BCCR-BCM2.0) }\end{array}$ & Run1 & -0.030 & -0.134 & 0.133 \\
\hline \multirow[t]{2}{*}{ CCSM3 } & Run 1 & -0.205 & -0.113 & -0.282 \\
\hline & Run 3 & -0.109 & -0.055 & -0.164 \\
\hline \multirow[t]{5}{*}{ CGCM3.1(T47) } & Run 1 & -0.342 & -0.229 & $-\mathbf{0 . 3 8 4}$ \\
\hline & Run 2 & -0.031 & -0.277 & 0.195 \\
\hline & Run 3 & -0.024 & -0.103 & 0.197 \\
\hline & Run 4 & -0.276 & -0.307 & -0.233 \\
\hline & Run 5 & 0.228 & 0.211 & 0.224 \\
\hline CGCM3.1(T63) & Run 1 & -0.077 & -0.433 & 0.222 \\
\hline $\begin{array}{l}\text { Centre National de Recherches Météorologiques Coupled } \\
\text { Global Climate Model, version } 3 \text { (CNRM-CM3) }\end{array}$ & Run 1 & 0.077 & 0.268 & -0.097 \\
\hline CSIRO-Mk3.0 & Run 1 & -0.041 & 0.061 & -0.151 \\
\hline CSIRO-Mk3.5 & Run 1 & -0.407 & -0.500 & -0.329 \\
\hline \multirow[t]{3}{*}{ ECHAM5/MPI-OM } & Run 1 & -0.275 & -0.027 & -0.518 \\
\hline & Run 2 & -0.601 & -0.547 & -0.647 \\
\hline & Run 3 & -0.460 & -0.539 & -0.336 \\
\hline \multirow{3}{*}{$\begin{array}{l}\text { Flexible Global Ocean-Atmosphere-Land System Model } \\
\text { gridpoint version 1.0 (FGOALS-g1.0) }\end{array}$} & Run 1 & -0.284 & -0.213 & -0.374 \\
\hline & Run 2 & -0.257 & -0.176 & -0.345 \\
\hline & Run 3 & -0.318 & -0.320 & -0.382 \\
\hline GFDL CM2.0 & Run 1 & -0.425 & -0.389 & -0.479 \\
\hline GFDL CM2.1 & Run 1 & -0.483 & -0.544 & -0.431 \\
\hline \multirow{2}{*}{ GISS Atmosphere-Ocean Model (GISS-AOM) } & Run 1 & -0.148 & -0.353 & 0.037 \\
\hline & Run 2 & 0.104 & 0.213 & 0.099 \\
\hline \multirow[t]{3}{*}{ GISS-EH } & Run 1 & -0.131 & -0.317 & 0.126 \\
\hline & Run 2 & 0.127 & -0.075 & 0.366 \\
\hline & Run 3 & 0.300 & 0.235 & 0.379 \\
\hline \multirow[t]{2}{*}{ GISS-ER } & Run 2 & -0.210 & -0.403 & 0.054 \\
\hline & Run 4 & -0.204 & -0.027 & -0.378 \\
\hline $\begin{array}{l}\text { Instituto Nazionale di Geofisica e Vulcanologia Scale Interaction Experiment } \\
\text { (INGV-SXG) }\end{array}$ & Run 1 & 0.057 & 0.264 & -0.230 \\
\hline Institute for Numerical Mathematics Coupled Model, version 3.0 (INM-CM3.0) & Run 1 & 0.017 & -0.283 & 0.149 \\
\hline IPSL CM4 & Run 1 & $-\mathbf{0 . 3 0 7}$ & $-\mathbf{0 . 3 3 8}$ & -0.271 \\
\hline MIROC3.2 high-resolution version [MIROC3.2 (hires)] & Run 1 & 0.224 & 0.121 & 0.289 \\
\hline \multirow[t]{3}{*}{ MIROC3.2 (medres) } & Run 1 & 0.014 & 0.259 & $-\mathbf{0 . 3 1 0}$ \\
\hline & Run 2 & 0.197 & 0.062 & 0.367 \\
\hline & Run 3 & 0.103 & 0.303 & -0.041 \\
\hline \multirow[t]{5}{*}{ MRI-CGCM2.3.2 } & Run 1 & -0.246 & -0.101 & -0.441 \\
\hline & Run 2 & -0.423 & -0.597 & -0.282 \\
\hline & Run 3 & -0.435 & -0.567 & -0.267 \\
\hline & Run 4 & -0.457 & -0.163 & -0.603 \\
\hline & Run 5 & -0.375 & -0.218 & -0.548 \\
\hline \multirow[t]{3}{*}{ PCM } & Run 1 & -0.211 & -0.216 & -0.216 \\
\hline & Run 3 & -0.138 & -0.262 & -0.049 \\
\hline & Run 4 & -0.567 & -0.664 & -0.426 \\
\hline $\begin{array}{l}\text { Third climate configuration of the Met Office (UKMO) Unified Model } \\
\text { (UKMO-HadCM3) }\end{array}$ & Run 1 & -0.200 & -0.021 & -0.339 \\
\hline Hadley Centre Global Environmental Model version 1 (UKMO-HadGEM1) & Run 1 & -0.084 & -0.052 & -0.101 \\
\hline
\end{tabular}

alone is adequate to produce positive and negative changes in correlation between the two subintervals that are as large as or larger than the observed change. This result is consistent with previous analyses of the skill of selected Atmospheric Model Intercomparison
Project (AMIP) GCM [ensembles from both the Community Climate Model version 3.6 (CCM3.6) and NASA GISS SI2000 GCMs] in representing the structure and interannual variability of the western Pacific summer monsoon (Chan and Evans 2002). 


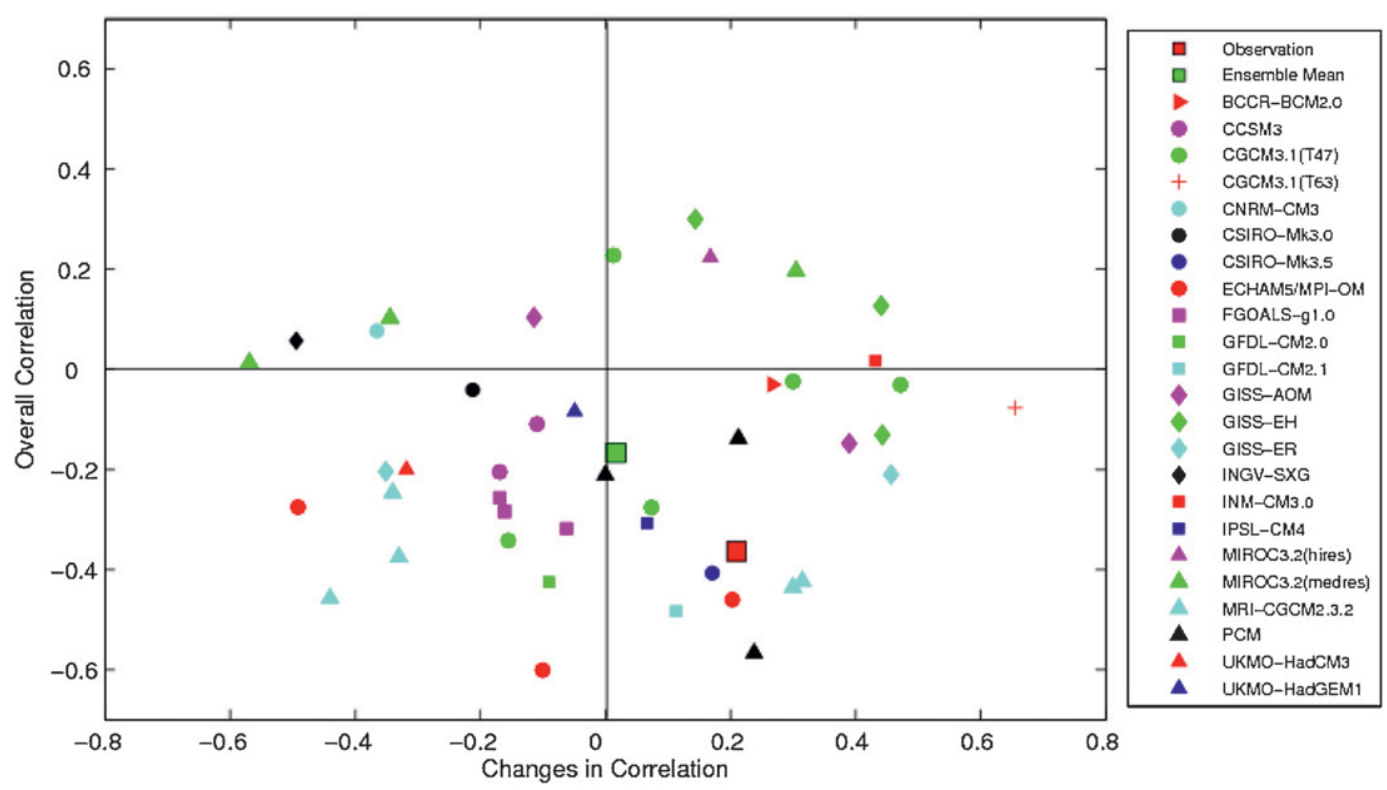

FIG. 4. Correlations between SASM IMI and niñograd series for the 23 models ( 44 realizations) for which ENSO mean state changes have been diagnosed. Shown are the average correlation over the full interval 1948-1998/99 (vertical axes) and the difference in correlation between the late (1974-1998/99) and early (1948-73) half intervals (horizontal axes). Results from a parallel analysis of observational data (NCEP-NCAR reanalysis data) and the averages over all simulations are shown for comparison.

It is nonetheless worthy of note that nine simulations [one run each of CGCM3.1 (T47), CSIRO-Mk3.5, ECHAM5/MPI-OM, GFDL CM2.1, GISS-ER, the L'Institut Pierre-Simon Laplace Coupled Model, version 4 (IPSL CM4), the Parallel Climate Model (PCM), and two runs of MRI-CGCM2.3.2] were able to capture both the substantial inverse overall relationship between the SASM and ENSO, and the recent weakening of this relationship (whether the later is forced or internal in nature). Given that GISS-ER is, again, among the seven best-performing models with regard to the SASM precipitation, there is reason to place some weight on its unique ability to reproduce the observed relationships.

Given the strong influence of ENSO on the SASM in general in the $20 \mathrm{c} 3 \mathrm{~m}$ model simulations, it is worth asking whether the spread observed in the behavior of the late-twentieth-century SASM in the $20 \mathrm{c} 3 \mathrm{~m}$ simulations can be explained by the divergence in the ENSO-trending nature of the different models. We thus reexamined the results shown in Fig. 3 within the context of whether particular models tend to project a more El Niño- or more La Niña-like mean state in response to greenhouse forcing, based on the analysis discussed in section 3. Given the current inverse relationship between ENSO and the SASM, we might expect that models that project a more El Niño-like (La Niña-like) mean state would, all other things being equal, project a weaker (stronger) SASM. Surprisingly, there is not a clear breakdown of the model results with respect to this consideration. There is a hint of a greater tendency for the El Niño-trending models to project a more negative trend in the IMI than the La Niña-trending models (Fig. 5), but the scatter is quite large, and clearly ENSO cannot be considered the dominant determining factor in the modeled trends in SASM strength. Given the current limitations in the fidelity of ENSO in state-of-the-art AOGCMs [as indicated, e.g., by the divergence of the projections of future changes in the ENSO mean state and in the CMIP3 simulations; e.g. Meehl et al. (2007)], and similar limitations in the fidelity of ENSO-monsoon relationships in the models (e.g., AchutaRao and Sperber 2002, 2006; Joseph and Nigam 2006), conclusions regarding the ENSO-SASM relationship from analyses of the CMIP3 simulations must be considered quite tentative.

\section{Conclusions}

The analyses performed here confirm a number of previous findings with respect to the late-twentiethcentury behavior of the SASM. They confirm the decreasing trend in SASM strength in recent decades, a very modest and statistically insignificant change in SASM-related precipitation, an inverse relationship between the SASM and ENSO, and a weakening of the latter relationship in recent decades. We find that this 

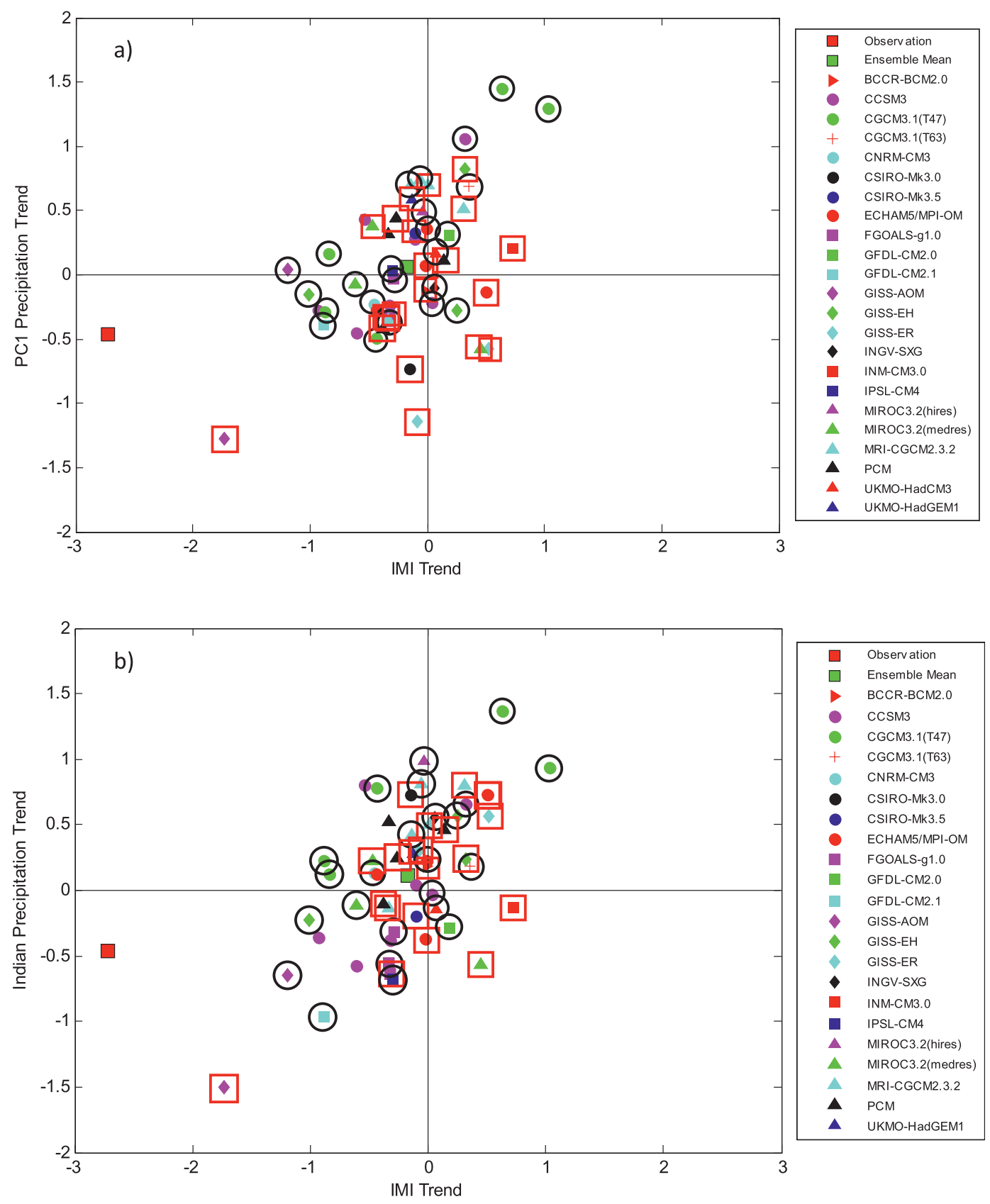

FIG. 5. Change in the SASM circulation and SASM-related precipitation as in (a) Fig. 2b and (b) Fig. 2d, but distinguishing models that project a more El Niño-like mean state (black circles) from those that project a more La Niña-like mean state (red squares) for the 23 models (44 realizations) for which ENSO mean state changes have been diagnosed.

pattern of behavior is reproduced in certain but not all respects in the CMIP3 historical 20c3m simulations. For example, the tendency for weakening of the SASM over the late twentieth century is reproduced in the $20 \mathrm{c} 3 \mathrm{~m}$ models, though the trend is substantially smaller than indicated by the observations. The weakening of the SASM in both the observations and the CMIP3 20c3m simulations is likely the result of a number of competing processes. Any tendency for strengthening of the SASM due to increased land-sea differential diabatic heating appears to be overwhelmed by other factors favoring weakening. These factors potentially include both the increase in static stability with warming and the response to anthropogenic tropospheric sulfate aerosol forcing. 
Parallel analyses of greenhouse-forced-only CMIP3 simulations are currently under way to tease apart the relative roles of these competing effects.

The model simulations suggest that the minor decrease in SASM-related precipitation is entirely within the range of the model's internal variability, and thus a forced signal cannot yet be discerned here. The lack of any clear change in SASM-related precipitation is consistent both with the wind-precipitation paradox, which explains how SASM-related precipitation need not decrease with a weakening SASM in an enhanced greenhouse, and the potential that anthropogenic aerosol forcing may be offsetting the impacts of any greenhouserelated tendencies for increased monsoonal precipitation.

Finally, we find that the $20 \mathrm{c} 3 \mathrm{~m}$ models on the whole reproduce the observed negative relationship between the SASM and ENSO. However, by contrast with claims elsewhere that this weakening trend may be a consequence of the anthropogenic forcing of climate, the $20 \mathrm{c} 3 \mathrm{~m}$ simulations indicate that such a weakening is entirely within the range of the model's internal variability. Such conclusions, however, must be considered as tentative given our current limitations in the faithfulness of the simulated processes underlying ENSO variability even in current-day, state-of-the-art AOGCMs.

Acknowledgments. We acknowledge the modeling groups, the Program for Climate Model Diagnosis and Intercomparison (PCMDI) and the WCRP's Working Group on Coupled Modeling (WGCM), for their roles in making available the WCRP CMIP3 multimodel dataset. Support of this dataset is provided by the Office of Science, U.S. Department of Energy.

\section{REFERENCES}

AchutaRao, K., and K. R. Sperber, 2002: Simulation of the El Niño Southern Oscillation: Results from the Coupled Model Intercomparison Project. Climate Dyn., 19, 191-209.

$\longrightarrow$, and —, 2006: ENSO simulation in coupled oceanatmosphere models: Are the current models better? Climate Dyn., 27, 1-15.

Annamalai, H., K. Hamilton, and K. R. Sperber, 2007: The South Asian Monsoon and its relationship with ENSO in the IPCC AR4 simulations. J. Climate, 20, 1071-1092.

Ashrit, R. G., K. Rupa Kumar, and K. Krishna Kumar, 2001: ENSO-monsoon relationship in a greenhouse warming scenario. Geophys. Res. Lett., 28, 1727-1730.

- , H. Douville, and K. Rupa Kumar, 2003: Response of the Indian monsoon and ENSO-monsoon teleconnection to enhanced greenhouse effect in the CNRM coupled model. J. Meteor. Soc. Japan, 81, 799-803.

- A. Kitoh, and S. Yukimoto, 2005: Transient response of ENSOmonsoon teleconnection in MRI-CGCM2.2 climate change simulations. J. Meteor. Soc. Japan, 83, 273-291.

Bengtsson, L., K. I. Hodges, and E. Roeckner, 2006: Storm tracks and climate change. J. Climate, 19, 3518-3543.
Blanford, H. F., 1886: The rainfall of India. Indian Meteor. Mem., 3, $1-269$.

Chan, S. C., and J. L. Evans, 2002: Comparison of the structure of the ITCZ in the west Pacific during the boreal summers of 1989-93 using AMIP simulations and ECMWF reanalysis. J. Climate, 15, 3549-3568.

Ding, Y. H., C. Y. Li, and Y. J. Liu, 2004: Overview of the South China Seas monsoon experiment. Adv. Atmos. Sci., 21, 343-360.

Douville, H., and Coauthors, 2000: Impact of $\mathrm{CO}_{2}$ doubling on the Asian summer monsoon: Robust versus model-dependent responses. J. Meteor. Soc. Japan, 78, 421-439.

Fan, F., M. E. Mann, and C. M. Ammann, 2009: Understanding changes in the Asian summer monsoon over the past millennium: Insights from a long-term model simulation. J. Climate, 22, 1736-1748.

Gershunov, A., N. Schneider, and T. Barnett, 2001: Low-frequency modulation of the ENSO-Indian monsoon rainfall relationship: Signal or noise? J. Climate, 14, 2486-2492.

Goswami, B. N., V. Krishnamurthy, and H. Annamalai, 1999: A broad-scale circulation index for the interannual variability of the Indian summer monsoon. Quart. J. Roy. Meteor. Soc., 125, 611-633.

Grove, R. H., 1998: Global impact of the 1789-93 El Niño. Nature, 393, 318-319.

Halley, E., 1686: An historical account for the trade winds, and monsoons, observable in the seas between the Tropics, with an attempt to assign the physical cause of the said winds. Philos. Trans. Roy. Soc. London, 16, 153-168.

Holton, J. R., 1992: An Introduction to Dynamic Meteorology. 3rd ed. Academic Press, 511 pp.

Hu, Z. Z., M. Latif, E. Roeckner, and L. Bengtsson, 2000: Intensified Asian summer monsoon and its variability in a coupled model forced by increasing greenhouse gas concentrations. Geophys. Res. Lett., 27, 2681-2684.

Hurrell, J. W., and K. E. Trenberth, 1998: Difficulties in obtaining reliable temperature trends: Reconciling the surface and satellite microwave sounding unit records. J. Climate, 11, 945-967.

Joseph, P. V., and P. L. Raman, 1966: Existence of low level westerly jet stream over peninsular India during July. Ind. J. Meteor. Geophys., 17, 407-410.

Joseph, R., and S. Nigam, 2006: ENSO evolution and teleconnection in IPCC's twentieth-century climate simulation: Realistic representation? J. Climate, 19, 4360-4377.

Kalnay, E., and Coauthors, 1996: The NCEP/NCAR 40-Year Reanalysis Project. Bull. Amer. Meteor. Soc., 77, 437-471.

Kitoh, A., S. Yukimoto, A. Noda, and T. Motoi, 1997: Simulated changes in the Asian summer monsoon at times of increased atmospheric $\mathrm{CO}_{2}$. J. Meteor. Soc. Japan, 75, 1019-1031.

Koteswaram, P., 1958: Easterly jet stream in the tropic. Tellus, 10, 43-57.

Kripalani, R. H., and A. Kulkarni, 1997: Climatic impact of El Niño/ La Niña on the Indian monsoon: A new perspective. Weather, 52, 39-46.

— - _ , and S. S. Sabade, 2001: El Niño-Southern Oscillation, Eurasian snow cover and the Indian monsoon rainfall. Proc. Ind. Natl. Sci. Acad., 67A, 361-368.

_ , and Coauthors, 2003: Indian monsoon variability in a global warming scenario. Nat. Hazards, 29, 189-206.

Krishna Kumar, K., B. Rajagopalan, and M. A. Cane, 1999: On the weakening relationship between the Indian monsoon and ENSO. Science, 284, 2156-2159. 
M. Hoerling, G. Bates, and M. A. Cane, 2006: Unraveling the mystery of monsoon failure during El Niño. Science, 314, 115-119.

Latif, M., A. Sterl, M. Assenbaum, M. M. Junge, and E. MaierReimer, 1994: Climate variability in a coupled GCM. Part II: The India Ocean and monsoon. J. Climate, 7, 1449-1462.

May, W., 2002: Simulated changes of the Indian summer monsoon under enhanced greenhouse gas concentrations in a global time-slice experiment. Geophys. Res. Lett., 29, 1118, doi:10.1029/ 2001GL013808.

_ 2004: Potential future changes in the Indian summer monsoon due to greenhouse warming: Analysis of mechanisms in a global time-slice experiment. Climate Dyn., 22, 389-414.

Meehl, G. A., and W. M. Washington, 1993: South Asian summer monsoon variability in a model with doubled atmospheric carbon dioxide concentration. Science, 260, 1101-1104.

—_, and J. M. Arblaster, 2003: Mechanisms for projected future changes in South Asian monsoon precipitation. Climate Dyn., 21, 659-675.

— W. M. Washington, D. J. Erickson III, B. P. Briegleb, and P. J. Jaumann, 1996: Climate change from increased $\mathrm{CO}_{2}$ and direct and indirect effects of sulfate aerosols. Geophys. Res. Lett., 23, 3755-3758.

_ and Coauthors, 2007: Global climate projections. Climate Change 2007: The Physical Science Basis, S. Solomon et al., Eds., Cambridge University Press, 747-845.

Mehta, V. M., and K.-M. Lau, 1997: Influence of solar irradiance on the Indian monsoon-ENSO relationship at decadalmultidecadal time scales. Geophys. Res. Lett., 24, 159-162.

Menon, S., J. Hansen, L. Nazarenko, and Y. Luo, 2002: Climate effects of black carbon aerosols in China and India. Science, 297, 2250-2253.

Mitchell, J. F. B., and T. C. Johns, 1997: On modification of global warming by sulfate aerosols. J. Climate, 10, 245-267.
Nigam, S., 1994: On the dynamical basis for the Asian summer monsoon rainfall-El Niño relationship. J. Climate, 7, 1750-1770.

Parthasarathy, B., R. R. Kumar, and D. R. Kothawale, 1992: Indian summer monsoon rainfall indices, 1871-1990. Meteor. Mag., 121, 174-186.

— A. A. Munot, and D. R. Kothawale, 1994: All-India monthly and seasonal rainfall series: 1871-1993. Theor. Appl. Climatol., 49, 217-224.

Ramanathan, V., and G. Carmichael, 2008: Global and regional climate changes due to black carbon. Nat. Geosci., 1, 221-227. , and Coauthors, 2005: Atmospheric brown clouds: Impacts on South Asian climate the hydrological cycle. Proc. Natl. Acad. Sci. USA, 102, 5326-5333.

Rasmusson, E. M., and T. H. Carpenter, 1983: The relationship between eastern equatorial Pacific sea surface temperature and rainfall over India and Sri Lanka. Mon. Wea. Rev., 111, 517-528.

Ropelewski, C. F., and M. S. Halpert, 1987: Global and regional scale precipitation patterns associated with the El Niño/ Southern Oscillation. Mon. Wea. Rev., 115, 1606-1626.

$\longrightarrow$, and 1989: Precipitation patterns associated with the high index phase of the Southern Oscillation. J. Climate, 2, 268-284.

Solomon, S., D. Qin, M. Manning, M. Marquis, K. Averyt, M. M. B. Tignor, H. L. Miller Jr., and Z. Chen, Eds., 2007: Climate Change 2007: The Physical Sciences Basis. Cambridge University Press, 996 pp.

Wang, B., 2006: The Asian Monsoon. Springer, 787 pp.

Webster, P. J., and S. Yang, 1992: Monsoon and ENSO: Selectively interactive system. Quart. J. Roy. Meteor. Soc., 118, 877-926.

_ , V. O. Magana, T. N. Palmer, J. Shukla, R. A. Tomas, M. Yanai, and T. Yasunari, 1998: Monsoons: Processes, predictability, and the prospects for prediction. J. Geophys. Res., 103, 14 45114510. 